\title{
Comenius on Chinese Teaching Method
}

\author{
Ruoyu Zhu, Jumei Xiao \\ Huzhou Teachers College, Zhejiang, China
}

\begin{abstract}
Comenius proposed many educational thoughts and methods in The Great Didactic, including the interpretation of Chinese teaching methods, which accurately shows the characteristics of verbal nature, limitations, and situations of Chinese teaching. In this way, we can observe the relevant conditions proposed by Comenius for these characteristics, mainly including things recognition, stage change, and sensory contact. Based on this, Comenius's point of view in the Chinese teaching method can be used for reference and enlightenment to the current Chinese teaching strategies, that is, the Chinese teaching should realize the verbal nature of Chinese teaching in the cognition of things, control the limitations of Chinese teaching in the stage change, and develop the situational nature of Chinese teaching in the sensory contact, etc.
\end{abstract}

Keywords: Comenius, The Great Didactic, Chinese teaching

\section{Introduction}

In 1632, Comenius published The Great Didactic, which symbolized the formal birth of teaching theory as an independent subject. The book comprehensively expounds the purpose, thought, method, and organization form of teaching. Some researchers believe that "in addition to the narrow sense of teaching, Comenius also integrates a lot of interpretation of educational issues. The meaning of the word 'didactic' used by Comenius is much broader than people's understanding of the meaning of 'teaching theory' in nowadays and is synonymous with 'education'” (Cui, 1997, pp. 16-20). In fact, the explanation of the content of Chinese teaching method in the book The Great Didactic contains the characteristics of Chinese teaching in the present sense, the conditions and methods to realize the characteristics of Chinese teaching.

\section{The Verbal Nature of Chinese Teaching and the Practicality of Things Recognition}

Chinese knowledge is complex, huge, and also very perceptual. These natures of Chinese are remarkable and make Chinese teaching different from other subjects, and have the characteristics of Chinese. The most essential feature is the verbal nature of Chinese teaching. In Comenius' view, this feature is reflected in the practice of things' cognition through speech activities, emphasizing that Chinese learning should be combined with things' learning.

\section{The Verbal Nature of Chinese Teaching}

Some scholars believe that Chinese teaching should focus on cultivating people's cultural literacy. Others believe that Chinese teaching should emphasize the practicality of Chinese. These views seem a little extreme. When Comenius (2014) discussed the chapter of Chinese teaching method, he said at the beginning that

Ruoyu Zhu, B.A., College of Teacher Education, Huzhou Teachers College.

Jumei Xiao, Ph.D., associate professor, College of Teacher Education, Huzhou Teachers College. 
"learning Chinese is not because they are a part of erudition or wisdom, but because they are a means for us to acquire knowledge and pass it on to others” (pp. 139-144). In other words, the function of Chinese teaching is not only to cultivate people's wisdom, knowledge, and quality, but also a practical means. On the basis of the above views, some scholars further pointed out that "the nature of Chinese curriculum should be surnamed language". "We should not overemphasize the 'humanity' to make the Chinese curriculum go to the generalization of the curriculum boundary, nor only regard the Chinese as the objective knowledge and tool outside the learning subject” (Zhao, 2012, pp. 54-56). In other words, for the course of Chinese, whether the function in humanity or instrumentality, points to the most basic verbal features of Chinese, which need to be mastered. Of course, "parole” is not equal to "language”, and "parole” reflects a subject's activity and behavior. Therefore, as a language subject, the teaching form of Chinese should be mainly verbal activities, so as to form and develop students' humanistic quality and improve their language expression ability. Comenius also expounded the methods and principles of language learning in The Great Didactic, so we cannot ignore that "the verbal nature is the most significant characteristic that distinguishes Chinese course from other courses" (Zhao, 2012, pp. 54-56).

\section{Realizing the Verbal Nature of Chinese Teaching in the Cognition of Things}

Comenius (2014) believed that "the knowledge of facts and the ability to express facts should be advanced synchronously" (pp. 139-144), his reason is that "learning written words should not leave the things they represent, because things do not exist separately and no words cannot be understood. They are both coexisting, performing their functions together”. That is to say, the study of Chinese should be connected with the study of things, which is a relationship between thinking and specific things: Language is the carrier of thinking and specific things are the content of thinking. Thinking reflects and expresses concrete things with the help of language and characters. Chinese learning is a way to cultivate thinking and understand things. It seems that there must be mutual promotion between Chinese teaching and the understanding of things.

In addition, people gradually form the cognition of the objective things in the long-term practical activities. Therefore, the cognition of things inevitably has the characteristics of practicality, which can be well reflected in the language activities of Chinese teaching, so as to realize the verbal nature of Chinese teaching. Comenius (2014) further pointed out that, "It is easier to learn all languages by practice than by rules" (pp. 139-144). The practice mentioned here is just a verbal activity. In Comenius’ view, only by practicing listening, speaking, reading, and writing, imitating with tongue and other similar verbal practices, and obtaining experience summary from the cognition of things, can we thoroughly learn the subject of Chinese. It can be said that the learning experience from practice is more thorough and profound than the teaching result of directly telling students the rules. Nevertheless, that does not mean rules are useless. On the contrary, the understanding of rules can in turn strengthen the knowledge from practice, and the process of practice will also promote students' understanding of rules, or even draw inferences from one instance to ask questions about rules. From this point of view, there is no right or wrong in practice and rules. The key is how educators deal with the relationship and order among them.

In a word, in the process of Chinese teaching, we should provide students with appropriate space and time, let them carry out verbal practice activities, and gradually master the basic principles and speech foundation of Chinese learning, and pay attention to the teaching sequence of practice before rules in the process of practice. Just like a child who learns to write, it is better to let him accumulate corpus, practice making sentences, and 
read books before teaching him some small skills than to directly tell him the exquisite theoretical methods.

\section{Limitations of Chinese Teaching and Stages of Individual Development}

The object of Chinese teaching is students individual whose physical and mental development has obvious stage characteristics. The subjective factors of students and the objective factors of Chinese itself define the limitations of Chinese teaching. Only by considering the two characteristics of stage and limitation, can we advance Chinese teaching step by step.

\section{Limitations of Chinese Teaching}

Comenius (2014) pointed out that, "No matter what language, it is unnecessary to have complete and detailed knowledge of it. If someone wants to achieve this goal, it is absurd and useless" (pp. 139-144). Now, it seems that this statement may not be accurate, and it is not entirely unnecessary to learn the complete and subtle knowledge of Chinese, but Comenius emphasized the limitations of Chinese teaching to a certain extent. This limitation is mainly reflected in the contradiction between Chinese teaching materials and students' physical and mental development level which includes the development level of students' cognition and students' psychology.

From the perspective of students' cognition, due to the development of human civilization and the possibility of unexplored knowledge field, the knowledge contained in Chinese must be complex and infinite, while the cognitive ability of human beings is limited. The existence of this contradiction means that we cannot learn all Chinese, but only a part of it. Therefore, especially for the students who still learn Chinese, those "materials crammed with what are extremely incompatible with their children's understanding" (Comenius, 2014, pp. 139-144) obviously violate the cognitive characteristics of students, and also ignore the limitations of Chinese teaching. However, even Chinese teaching materials that are suitable for students' cognitive range and understanding are not the best teaching materials. According to Comenius (2014), “Children's intelligence and language should be practiced in the materials that attract them” (pp. 139-144). Therefore, from the perspective of students' psychology, if all Chinese teaching materials are only for the purpose of students' understanding, then Chinese teaching will become a process of teachers' instilling knowledge, losing the interest and motivation of students' active learning. Students' psychological characteristics are reflected in students' attitudes towards learning materials, which can also help teachers to select which Chinese teaching materials are applicable. Therefore, in the process of Chinese teaching, due to the limited materials to attract students, that is, the students' psychological choice of teaching materials is limited, while the original Chinese teaching materials are infinite. Therefore, Chinese teaching will also be limited.

However, this does not mean that all Chinese teaching materials must attract students or that they can be used as long as they attract students. Instead, it is necessary to select appropriate teaching materials that attract students on the basis of materials that students can understand, and most of these materials are used for students' practice. That is to say, if a material is more obscure, does not conform to students' cognition or does not conducive to students' mental development, then it is not desirable even if the material can attract students enormously. That is to say, all Chinese teaching should be based on students' understanding and suitability.

\section{Control the Limitation of Chinese Teaching in the Stage Change}

The so-called "stage change" refers to the change of physical and mental characteristics, needs, and knowledge acceptance of people in different periods, reflecting the stage of individual development. This 
periodicity has a great influence on students' learning content and teachers' teaching structure. To this end, Comenius divides the four periods of language learning (as shown in Figure 1 below). Although his explanation is relatively rough, he has taken into account the stage changes of students' physical and mental characteristics and cognitive ability, and put forward more completely the teaching objectives of the four stages of language learning: speaking vaguely, speaking correctly, speaking beautifully, and speaking expressively.

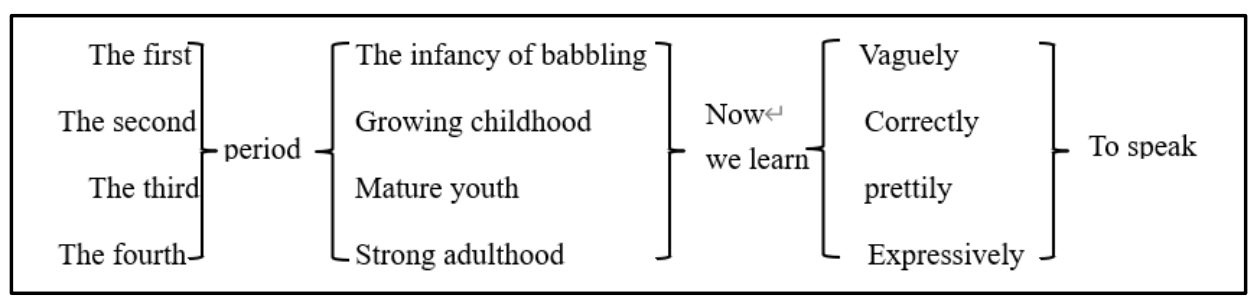

Figure 1. Four periods of language learning.

It can be said that it is the stage of individual development that leads to the limitations of Chinese teaching. Therefore, teachers should control the limitations of Chinese teaching in the stage changes. The Great Didactic has repeatedly mentioned that "do not need to learn all languages, as long as the necessary limit of learning" (Comenius, 2014, pp. 139-144). What teachers teach should meet the needs of students for Chinese knowledge at a certain stage and should not exceed the scope of students' understanding. That is to say, Chinese is related to all aspects of our real life, and even involves a lot of knowledge in all stages. Considering the limitations of Chinese teaching, we do not need to learn all Chinese. Of course, it is impossible for us to study thoroughly. For this reason, teachers should first investigate the learning situation as much as possible and pay attention to the physical and mental development characteristics of students, providing Chinese materials suitable for students to learn and understand in a certain stage in the proper and gradual teaching process, and set up stage goals appropriately according to these characteristics. Then, teachers can put this teaching principle into a class and analyze the common characteristics of middle school students in the same stage, at same time, paying attention to every student in the class and summarizing their personality in physical and mental development. Different students have different characteristics and needs in the same stage, so the limits of individual learning Chinese knowledge are not the same.

Based on this, teachers should pay attention to the students' subjectivity and diversity in the process of Chinese teaching, master the common characteristics of students in different stages and the outstanding characteristics of students, and control the limitations of Chinese teaching. A teacher's good command of Chinese teaching can be reflected by comprehensively understanding students and setting moderate phased goals. We all know that spoon-feeding students in order to expand students' horizon of Chinese knowledge is not a good teaching method for teachers, but it still be ignored by some people unconsciously. For example, a low-grade student cannot understand truths in some works, but some teachers like to explain these truths from their own point of view. In the process of enjoying preaching, they do not focus on what the students really master. If so, the students are likely to have the fault phenomenon of Chinese knowledge in learning, which is not conducive to the gradual development of mind. We all know that a child always has to learn from babbling to speaking and then to making a speech. In fact, the process of Chinese teaching should also be like this, "nature does not leap forward” (Comenius, 2014, pp. 139-144). 


\section{The Situational Nature of Chinese Teaching and the Intuitiveness of Sensory Contact}

The great teaching theory emphasizes the intuitiveness of sensory teaching for many times, which can create a more real and profound teaching situation, especially the Chinese subject which emphasizes emotional experience. Appropriate use of human senses as teaching aids can greatly promote the application and play of situational.

\section{The Situational Nature of Chinese Teaching}

Chinese is a way of understanding the world mainly by language and characters, which has rich perceptual color and is closely related to our living environment and emotional feelings. Therefore, Chinese teaching has the characteristics of situational nature. "Big Teaching Theory" points out, "When learning a new language, the initial practice must start with familiar subjects” (Comenius, 2014, pp. 139-144). Comenius believed that language learning needs a familiar subject matter, as well as a familiar and specific environment. If we can cognize something new in a familiar situation, we will understand the situation and specific meaning of this new thing more easily. In teaching, this kind of familiar situation is created by teachers, which can promote students' autonomy and inquiry in learning, and give Chinese teaching a possibility with more sense of picture and dynamic beauty. In addition, although this kind of situation is for open teaching, due to the limitations of Chinese teaching, the content of teaching is still limited, and the situation of Chinese teaching also needs to be limited. Furthermore, "Situational nature means that effective Chinese teaching should always revolve around a certain knowledge problem situation, which is one of the unique characteristics of Chinese teaching” (Zhao, 2012, pp. 54-56), the situation around a certain problem will not be too vague, nor will it use the standard answers to restrain students, but use all conditions to create exploration and discovery situations for students, which is the significance of situational characteristics of Chinese teaching.

\section{Developing the Situational Nature of Chinese Teaching in Sensory Contact}

According to Comenius, “All knowledge begins with the senses” (Comenius, 2014, pp. 139-144). Sense organ includes vision, hearing, smell, taste, skin sense, motion sense, and organism sense. At present, in Chinese teaching, the most commonly used senses are vision, hearing, and kinesthetic sense, which are mainly used to complete students' listening, watching, and classroom performance activities. Through the senses, students can directly see, hear, and feel the real situation described by the language. Although Comenius did not clearly put forward a new term of Chinese teaching method, his point of view shows that in the process of Chinese teaching, this kind of intuitive feeling can make abstract knowledge become concrete image. Setting familiar and attractive subjects not only takes into account the limitations of Chinese teaching, but also creates concrete situation in Chinese teaching. The teaching method by situations "contribute to the formation of students' perceptual knowledge” (Wang, 2013, p. 45) and the improvement of Chinese literacy depends on the perceptual cognitive ability of students. As Comenius said, perception should be prior to cognition. Knowledge understanding should first complete the perception of things, and then get further explanation of words. Especially, in the subject, such as Chinese, where there are almost no standard answers to many questions, it is very important for students to understand and feel as learning subjects, so we say that situational teaching is an indispensable method to achieve high-level Chinese teaching.

Chinese situational teaching can "exert a subtle influence on students' mind, cultivate students' aesthetic emotion, moral emotion and rational emotion, and achieve the ultimate goal of cultivating students' advanced emotion" (Li, 1991, pp. 27-33) different from the traditional Chinese teaching method, it does not teach 
knowledge and rule before students practice various problems, but directly subvert the order, that is, firstly to get through the students' sensory contact with the objective things to create the situation, stimulating the students' interest in learning, then to guide the students to think and summarize the solutions. When these students put into practice, they will associate the situation at the beginning and naturally feel familiar with and satisfied with themselves, which is conducive to the students' interpretation of the problem and the formation of inquiry thinking. For example, for the interpretation of a text, we can use role-playing, classroom games, audio appreciation, and other means to complete the dialogue with students. In addition, teachers can further innovate, through the sense of touch, smell, taste, and other senses which are seldom used at present, to set up teaching situations, so that students can touch, smell, and taste them when it is safe and feasible, so as to restore real and specific Chinese scenes for them.

Although the creation of situation as an ideal teaching mode has greatly enhanced the interest of Chinese teaching, this is not to prove that the traditional Chinese teaching method is not desirable at all. After all, the situation is created by people, with the inevitable sense of design and traces, and if the teachers guide improperly in the specific implementation, it may delay the progress of the course. Therefore, we should pay attention to some basic principles in Chinese situational teaching. Of course, in order to solve this problem, we can not only explore a better way to create and guide the situation, but also try to find a perfect way to combine the situation method and the traditional method in Chinese teaching by using the situation teaching to develop and guide students and using the traditional teaching to consolidate and strengthen knowledge.

\section{Conclusion}

Generally speaking, although The Great Didactic of Comenius has a strong religious color and some of his educational thoughts are limited to some extent, however, it bounds to say that his theory is undoubtedly a great progress compared with the dogmatism at that time. Even today, there is still a positive significance of guiding education and teaching. We must take a dialectical view of this book and the basic characteristics of Chinese teaching method. Through further exploration and unremitting efforts, we can find many clues which are possible to become a brand-new topic to solve today's Chinese teaching problems and pave the way for Chinese teaching.

\section{References}

Comenius, J. A. (2014). The Great Didactic (Vol. 2, pp. 139-144). (R. G. Fu, Trans.). Beijing: Education Science Press.

Cui, Y. Y. (1997). Historical evolution and interrelationship of teaching theory, curriculum theory and learning theory. Modern Education Review, 18(4), 16-20.

Li, J. L. (1991). Theory and practice of situational teaching. People's Education, 42(5), 27-33.

Wang, H. Z. (2013). The application of situational teaching in Chinese classroom. Middle School Teaching Reference, $5(31), 45$.

Zhao, X. X. (2012). The enlightenment of great teaching theory by Comenius on Chinese teaching practice. Journal of Northwest Adult Education, 14(4), 54-56. 